\title{
Resolução temporal e atenção seletiva de indivíduos com zumbido****
}

\author{
Temporal resolution and selective attention of individuals with \\ tinnitus
}

\begin{abstract}
Isabela Olszanski Acrani*
Liliane Desgualdo Pereira**
\end{abstract}

\begin{abstract}
*Fonoaudióloga. Mestre em Ciências pelo Programa de Distúrbios da Comunicação Humana do Departamento de Fonoaudiologia da Universidade Federal de São Paulo (Unifesp). Endereço para correspondência: R. Isaac Teodoro de Lima, 300 - Ribeirão Preto - SP CEP 14020-540 (belacrani@yahoo.com.br).

**Fonoaudióloga. Livre Docente pelo Departamento de Fonoaudiologia da Unifesp. Professora Associada e Livre Docente do Departamento de

Fonoaudiologia da Unifesp.

***Trabalho Realizado no Departamento de Fonoaudiologia da Unifesp com Apoio do CNPq.
\end{abstract}

Artigo Original de Pesquisa

Artigo Submetido a Avaliação por Pares

Conflito de Interesse: não

\begin{abstract}
Background: speech comprehension difficulty is a very common complaint of individuals with tinnitus with and without hearing loss. This study was conducted in order to analyze if tinnitus interferes in auditory processing and speech comprehension in individuals with normal hearing levels. Aim: to asses and compare the auditory behavior of temporal resolution and selective attention of adults with normal hearing levels with and without tinnitus. Method: 45 individuals, 15 with continuous tinnitus and 30 without tinnitus were selected and assessed by three auditory processing tests: Speech in Noise Test, Dichotic Digits Test and Gaps in Noise. After that, the results of each group were compared by appropriated statistic's tests; one of them was ANOVA. Results: there were no significant statistical differences between the groups and both ears. Conclusion: tinnitus did not interfere in the auditory abilities of selective attention and temporal resolution.
\end{abstract}

Key Words: Auditory Perception; Adult; Tinnitus.

\section{Resumo}

Tema: é comum a queixa de dificuldade de compreensão da fala em indivíduos que apresentam zumbido com ou sem perda auditiva. Para conhecer se o zumbido interfere no processamento auditivo e compreensão da fala em sujeitos com audiometria normal, foi realizado este trabalho. Objetivo: foi avaliar e comparar o comportamento auditivo de resolução temporal e de atenção seletiva de indivíduos adultos com audiometria normal, com e sem zumbido. Método: 45 indivíduos, 15 com zumbido constante e 30 sem zumbido, foram selecionados e avaliados por meio de três testes de processamento auditivo: Teste de Fala com Ruído Branco, Teste Dicótico de Dígitos e Gaps In Noise. Em seguida os resultados de cada grupo foram comparados entre si, utilizando testes estatísticos apropriados, dentre eles o ANOVA. Resultados: não foi observada diferença estatisticamente significante entre os grupos em ambas as orelhas. Conclusão: o zumbido não interferiu nas habilidades auditivas de atenção seletiva e resolução temporal.

Palavras-Chave: Percepção Auditiva; Adulto; Zumbido. 


\section{Introduction}

Tinnitus is the perception of a sound when no external source is emitting perceivable sound waves. It may be the main symptom of various diseases 1 . It is a condition found commonly around the world 2 .

To explain the physiology of tinnitus generation and perception cochlear and non-cochlear models were developed3. Due to lesions to the external or internal cilia or the auditory tract, spontaneous activities of the auditory system are altered and these are perceived as tinnitus. If this is perceived negatively or is an irritating sound, it will become an inconvenience and habituation will not occur4.

Tinnitus may occur in individuals with normal audiometry or with auditory loss5-7. When accompanied by normal audiometry the condition may be associated with attention deficit8, especially highly inconvenient tinnitus9,10.

Research involving subjects presenting auditory hearing loss 11 and normal hearing12,13 verified that tinnitus interferes with auditory processing and perception of speech in noisy environments for some hearing abilities.

Considering tinnitus affects speech comprehension and influences several auditory processes, it may probably be related to selective attention, temporal resolution and other sound processing abilities.

The present piece seeks to evaluate and compare temporal resolution and selective attention auditory behavior among adult individuals presenting normal audiometry, reporting tinnitus or not.

\section{Method}

Fifteen individuals with constant bilateral tinnitus and hearing spans up to $25 \mathrm{~dB}$ (NA) between 0.25 and $8.0 \mathrm{kHz}$ ( 3 men, 12 women, average age 23 years 3 months, ages between 20 and 27), hereafter known as the Study Group (SG), and thirty individuals presenting no tinnitus and hearing spans up to $25 \mathrm{~dB}$ (NA) between 0.25 and $8.0 \mathrm{kHz}(3$ men, 27 women, average age 21 years 8 months, ages between 19 and 30 years), hereafter the Control Group (CG), were selected from within the Undergraduate and Graduate student body of Universidade Federal de São Paulo (UNIFESP). This study was approved by the UNIFESP Research Ethics Committee under protocol 389/08. All participants signed a free informed consent document.
The participants were submitted to a tone span audiometry, logoaudiometry and impendanciometry. Individuals with hearing loss and/or middle ear alterations were excluded from the sample, as well as individuals from the control group who had problems with speech comprehension.

To identify the SG, information regarding the location and onset time of tinnitus was necessary. Individuals were also tested in order to measure the intensity and frequency of tinnitus and submitted to the Brazilian Tinnitus Handicap Inventory (Brazilian THI).

The THI is a questionnaire devised to quantify the inconvenience caused to the individual14. It was developed for use with the English Language and adapted for use with Portuguese 15.

It consists of a set of 25 questions with three possible answers, yes, no and sometimes. Yes was assigned four points, sometimes two points and no zero points. Thus the questionnaire possesses a 100-point maximum. Inconvenience levels were devised as follows: from zero to 16 points, as a negligible inconvenience; from 18 to 36 points, a mild inconvenience; between 38 and 56 points, a moderate inconvenience; from 58 to 76 points, a severe inconvenience; and from 78 to 100 points a catastrophic inconvenience16.

Both groups were submitted to an auditory processing behavior evaluation consisting of the Speech in Noise Test (SNT), the Dichotic Digits Test (DDT) and the Gaps-in-Noise Test (GIN).

The SNT evaluates selective attention ability (auditory closure). The normality criterion for correct responses was set as $70 \% 17$.

The DDT verifies selective attention ability (figure-background). The normality standard for adults is $95 \% 18$.

The GIN test is a new test that evaluates the temporal resolution ability, crucial for speech comprehension19. It is composed of a series of white noise segments presented at 50dB (NS), lasting six seconds each. Each segment may contain zero to three silence intervals (gaps) and these last 2, 3, 4, 5, 6, 8, 10, 12, 15 and 20 milliseconds (MS). The GIN test comprises four lists, each composed of several segments presenting each gap six times, and thus each list is composed of 60 gaps. In this study, list 1 was used for the right ear and list 2 for the left, lists 3 and 4 being omitted as they do not interfere in the result 20.

Each individual assessed was required to push a button every time they heard a silence interval amid the noise. The test was applied to both ears, beginning with the right ear in all cases. 
The result analysis comprised the span and percentage of gaps correctly indicated. The span was defined as the smallest gap which the individual was able to correctly identify four times. The percentage was calculated over the total number of gaps. The criterion for normality was established as a span of 5.43 milliseconds and a percentage of gaps indicated correctly as $67.25 \% 21$.

Statistical analysis

Statistical analysis of all data collected was initially done descriptively.

Interferential analyses employed to confirm or refute evidence found in the descriptive analysis were:

- Kolmogorov-Smirnov test to verify that distribution of test responses on the SNT, DDT and GIN followed normal distribution;

.Wilcoxon test comparing right and left ear response distribution for the SNT, DDT and GIN (span); . Mann-Whitney test comparing the distribution of responses for each group (tinnitus and no tinnitus) regarding data from the SNT, DDT and GIN (span); - Variance analysis with repeated measurements comparing average values on the GIN test (percentage of correct responses) for each group, considering both ears.

\section{Results}

For the study group, eight $(53.3 \%)$ individuals reported tinnitus for up to five years and seven (46.7\%) for over five years. Of the 15 individuals in this group, 13 reported tinnitus resembling a whistle (pure tone) and two reported resemblance with a waterfall (noise).
With regards to the intensity sensation, the average presented was $20.7 \mathrm{~dB}$ (NS) for the right ear $(\mathrm{DP}=11.4)$ and $17.5 \mathrm{~dB}(\mathrm{NS})$ for the left ear (DP = 15.5). Most individuals reported tinnitus frequency sensation around $6.0 \mathrm{kHz}$ and $8.0 \mathrm{kHz}$.

With regards to $\mathrm{THI}$, the average point score was 12.3 points ( $\mathrm{DP}=12.9)$ and, according to the grouping established, $11(73.3 \%)$ individuals presented negligible tinnitus, $3(20 \%)$ mild tinnitus and one $(6.7 \%)$ moderate tinnitus.

\section{SNT and DDT}

All individuals from both groups presented SNT and DDT results for both ears within the normality standard set prior to testing. The results can be found in tables 1 and 2. When comparing results for each ear, both groups presented data for the right ear which were statistically equal to those of the left ear for both the SNT and the DDT. Comparing results obtained for each group, the statistical tests applied revealed that readings for the study group were statistically equivalent to those obtained from the control group.

\section{Gaps in Noise}

Table 3 presents the results obtained in the GIN test.

In relation to span, the test results, when comparing ears, revealed the control group presented a statistically significant lower span for the right ear than the left. However, for the study group, the results were statistically equal for both ears. There was no group effect in this auditory perception test. 
TABLE 1. Abridged results for the SNT according to group and ear.

\begin{tabular}{lllll}
\hline g roup & & Right ear & Left ear & $\mathrm{p}^{\mathrm{a}}$ \\
No tinntius & mean & $96,5 \%$ & $96,4 \%$ & 0,796 \\
& median & $96,0 \%$ & $96,0 \%$ & \\
& minimum & $92,0 \%$ & $88,0 \%$ & \\
& maximum & $100,0 \%$ & $100,0 \%$ & \\
& Standard deviation & $2,9 \%$ & $3,4 \%$ & 0,131 \\
tinnitus & mean & $98,3 \%$ & $97,1 \%$ & \\
& median & $100,0 \%$ & $96,0 \%$ & \\
& minimum & $94,0 \%$ & $92,0 \%$ & \\
& maximum & $100,0 \%$ & $100,0 \%$ & \\
& & & \\
& Standard deviation & $2,3 \%$ & $3,1 \%$ & \\
& & 0,063 & 0,600 & \\
& & &
\end{tabular}

Key: ${ }^{a}$ descriptive level comparing ears (right and left); ${ }^{b}$ descriptive level comp aring groups (tinnitus and no tinnitus).

TABLE 2. Abridged results for DDT according to g roup and ear.

\begin{tabular}{lllll}
\hline g roup & & Right ear & Left ear & $\mathrm{p}^{\mathrm{a}}$ \\
No tinntius & mean & $99,5 \%$ & $99,4 \%$ & 0,675 \\
& median & $100,0 \%$ & $100,0 \%$ & \\
& minimum & $96,3 \%$ & $97,5 \%$ & \\
& maximum & $100,0 \%$ & $100,0 \%$ & \\
& Standard deviation & $0,9 \%$ & $0,8 \%$ & $>0,999$ \\
& mean & $99,3 \%$ & $99,3 \%$ & \\
& median & $100,0 \%$ & $100,0 \%$ & \\
& minimum & $95,0 \%$ & $95,0 \%$ & \\
& maximum & $100,0 \%$ & $100,0 \%$ & \\
& Standard deviation & $1,4 \%$ & $1,4 \%$ & \\
& & 0,801 & 0,549 &
\end{tabular}

Key: ${ }^{a}$ descriptive level comparing ears (right and left); ${ }^{b}$ descriptive level comparing groups (tinnitus and no tinnitus). 
Tab le 3. Abridged results for the GIN test according to grou p and ear.

\begin{tabular}{|c|c|c|c|}
\hline Group & Right ear average & Left ear a verage & $\mathrm{p}^{\mathrm{a}}$ \\
\hline \multirow[t]{2}{*}{ No tinnitus } & $4,7 \mathrm{~ms}(\mathrm{DP}=0,9)$ & $5,1 \mathrm{~ms}(\mathrm{DP}=1,0)$ & 0,002 \\
\hline & $72,6 \%(\mathrm{DP}=6,8)$ & $72,5 \%(\mathrm{DP}=5,9)$ & 0,950 \\
\hline \multirow[t]{2}{*}{ Tinnitus } & $4,7 \mathrm{~ms}(\mathrm{DP}=1,1)$ & $4,8 \mathrm{~ms}(\mathrm{DP}=0,4)$ & 0,564 \\
\hline & $72,5 \%(\mathrm{DP}=6,7)$ & $72,7 \%(\mathrm{DP}=7,3)$ & 0,950 \\
\hline $\mathrm{p}^{\mathrm{b}} \operatorname{span}$ & 0,950 & 0,216 & \\
\hline $\mathrm{p}^{\mathrm{b}}$ percentage & 0,978 & 0,978 & \\
\hline
\end{tabular}

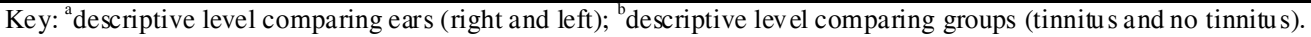

\section{Discussion}

\section{SNT}

In the present study individuals with tinnitus obtained results similar to those with no tinnitus. Regarding auditory closure ability, referred literature presented that individuals with normal audiometry and tinnitus performed significantly worse than individuals with normal audiometry and no tinnitus 12,13. Another study 11 observed that tinnitus interfered with auditory closure ability; however the authors used subjects with hearing loss.

The results obtained in the present piece were not similar to those found in literature 11-13.

\section{DDT}

Although there is no literature on studies using DDT to compare individuals presenting tinnitus and not, another test evaluating figurebackground ability was used, the SSW. When evaluating individuals with tinnitus and normal hearing and normal audiometry, the authors observed that the experimental group contained more individuals presenting alterations than the control group. However this difference was statistically insignificant. One may state that the comparisons between the Study Group and the Control Group with regards to figurebackground were similar to other studies. However, in the present study no individual yielded results under the normality standard set, while in literature there is a tendency that individuals with tinnitus present alterations to this ability 12,21.

\section{GIN}

In the present study there was no significant difference between the results for each ear for the tinnitus group, for both span and percentage. This was not the case for the control group, for which a statistically significant difference was found between ears in terms of span.

In specialized literature20,21 no differences were found for spans observed in right and left ears in individuals with normal audiometry and no tinnitus, as in the Study Group. However results in literature were different for the Control Group. 
Only one study verified statistically significant differences between lists 1 and 2, 1 having had a larger percentage of correct responses than 223 .

No significant differences were found when comparing result sets for each ear. This was true for both groups. This way the findings in the present study were different compared to one study 23 but similar to others, regarding adults, presenting tinnitus or not 20,21 .

The results for the GIN test also presented similarities between groups for both ears.

In a study applying the GIN test in individuals with normal audiometry and tinnitus, a significant difference between the groups was verified, the author observing that individuals with tinnitus had more difficulties with the temporal resolution ability than individuals with no tinnitus 24 .

Once again, the present study's findings differ from those in literature 24 .

\section{Final considerations}

For the present study the results of the three auditory processing tests were applied similarly to both groups, thus some hypotheses may be raised.

The first factor to consider is that in all other studies the experimental group subjects were selected from a hospital or clinic12,13,22,24. In the present study subjects were not sampled from a specialized medical service but were individuals presenting tinnitus but not being treated for it. Hence, subjects from other studies probably had more difficulty dealing with tinnitus and, consequently, this difficulty may have influenced day-to-day situations, including speech perception. Furthermore, individuals in the present study presented a lower degree of inconvenience caused by tinnitus whereas in specialized literature this was not the case 12,13 . Hence, individuals in the present study possessed the capacity to shift their focus of attention, making tinnitus a non-interfering factor, until the present moment, in speech processing.

Another factor to consider is in relation to the intensity sensation. In literature 12 , perceived loudness was observably higher in test subjects than in those in the present study. One may suggest that an increase in tinnitus intensity may in turn increase its importance to the individual and, consequently, interfere more with auditory perception.

Lastly, one final factor that may have influenced the results of the present study was the condition's etiology. In the present study, as was the case in literature 12,13,24, the cause for tinnitus was not researched. It is likely that the origin of the problem may influence the research of alterations in speech processing. In the present study no sampled individual reported centrally located tinnitus. If the alteration is peripheral, perhaps it does not interfere in signal transmission through the auditory tract. Another important etiological factor to be considered is conditions external to the auditory system that may cause tinnitus. Due to the fact that tinnitus is the result of problems unrelated to either peripheral or central hearing, this symptom will probably not cause any auditory changes, neither to audibility spans nor to auditory processing.

One suggests that for similar research individuals with normal hearing and etiologically diagnosed tinnitus should be sampled.

\section{Conclusion}

Tinnitus of mild inconvenience and perceived intensity of around $19 \mathrm{~dB}$ NS and perceived frequency of around $6.0 \mathrm{kHz}$ and $8.0 \mathrm{kHz}$ did not interfere in selective attention and temporal resolution auditory abilities, which were similar to those of individuals presenting no tinnitus. 


\section{References}

1. Eggermont JJ. Central Tinnitus. Auris Nasus Larynx. 2003;30 Suppl:S7-12.

2. Heller AJ. Classification and epidemiology of tinnitus. Otolaryngol Clin N Am. 2003;36(2):239-48.

3. Baguley DM. Mechanisms of tinnitus. British Medical Bulletin. 2000;63:195-212.

4. Jastreboff PJ, Gray WC, Gold SL. Neurophysiological Approach to Tinnitus Patients. Am J. Otol. 1996;17: 23640 .

5. Weisz N, Hartmann T, Dohrmann K, Schlee W, Norena A. High-frequency tinnitus without hearing loss does not mean absence of deafferentation. Hear Res. 2006;222(12):108-14

6. Borghi C, Modugno GC, Brandolini C, Pirodda A. Is tinnitus useful in early detection of incoming heart decompensation? Med Hypotheses. 2006;67(3):437-9.

7. Pirodda A, Esposti DD, Brandolini C, Modugno GC, Cosentino E, Borghi C. Could echocardiography yield a cardiovascular profile of the tinnitus prone subject? Med Hypotheses. 2008;70(2):252-4.

8. Stevens C, Walker G, Boyer M, Gallagher M. Severe tinnitus and its effect on selective and divided attention. Int J Audiol. 2007;46(5):208-16.

9. Delb W, Strauss DJ, Low YF, Seidler H, Rheinschmitt A, Wobrock T, et al. Alterations in Event Related Potentials (ERP) Associated with Tinnitus Distress and Attention. Appl Psychophysiol Biofeedback. 2008;33(4):211-21.

10. Walpurger V, Hebing-Lennartz G, Denecke H, Pietrowsky R. Habituation deficit in auditory event-related potencials in tinnitus complainers. Hear Res. 2003;181(1-2):57-64.

11. Newman CW, Wharton JA, Shivapuja BG, Jacobson GP. Relationships among psychoacoustic judgments, speech understanding ability and self-perceived handicap in tinnitus subjects. Audiology. 1994 Jan-Fev;33(1):47-60.

12. Branco-Barreiro FCA. Zumbido em adultos ouvintes normais: um estudo sobre o processamento auditivo central e o handicap [Tese]. São Paulo(SP): Pontifícia Universidade Católica de São Paulo; 1998.

13. Huang CY, Lee HH, Chung KC, Chen HC, Shen YJ, Wu JL. Relationships among Speech Perception, Self-Rated Tinnitus Loudness and Disability in Tinnitus Patients with Normal Pure-Tone Thresholds of Hearing. ORL. 2007;69 (1):25-9.
14. Ferreira PEA, Cunha F, Onishi ET, Branco FCA, Ganança FF. Tinnitus Handicap Inventory: adaptação cultural para o Português Brasileiro. Pró-fono 2005;17(3): 303-10.

15. Newman CW, Jacobson GP, Spitzer JB. The development of the Tinnitus Handicap Inventory. Arch. Otolaryngol. Head Neck Surg. 1996;122(2):143-8.

16. McCombe A, Baguley D, Coles R, McKenna L, McKinney $\mathrm{C}$, Windle-Taylor P, et al. Guidelines for the grading of tinnitus severity: the results of a working group commissioned by the British Association of Otolaryngologists, Head and Neck Surgeons. Clin Otolaryngol. 2001;26(5):388-93.

17. Pereira LD. Avaliação do processamento auditivo central. In: Lopes Filho O, Campiotto AR, Levy C, Redondo MC, Bastos WA (org). Tratado de Fonoaudiologia. $2^{\mathrm{a}}$ ed. São Paulo: Tecmedd; 2005. p. 111-30.

18. Pereira LD. Processamento auditivo central: uma revisão crítica [tese]. São Paulo(SP): Universidade Federal de São Paulo; 2005.

19. Gage N, Roberts TPL, Hickok. Temporal resolution properties of human auditory cortex: reflections in the neuromagnetic auditory evoked M100 component. Brain Res. 2006;1069(1):166-71.

20. Musiek FE, Shinn JB, Jirsa R, Bamiou DE, Baran JA, Zaidan E. GIN (Gaps-In-Noise) Test Performance in Subjects with Confirmed Central Auditory Nervous System Involvement. Ear Hear. 2005;26(6):608-18.

21. Samelli AG, Schochat E. The gaps-in-noise test: Gap detection thresholds in normal-hearing young adults. Int $\mathrm{J}$ Audiol. 2008;47(5):238-45.

22. Branco-Barreiro FCA, Faria AG, Feroldi D, Dias PAS. Investigação audiológica em ouvintes com zumbido. Rev. Soc. Bras. Fonoaudiol. 2000:5(7);22-7.

23. Perez A. Estudo dos limiares de detecção de GAP, com o uso do teste GIN, em crianças de 11 e 12 anos [tese]. São Paulo(SP): Universidade Federal de São Paulo; 2008.

24. Sanches SGG. Função coclear e resolução temporal em indivíduos com zumbido [tese]. São Paulo(SP): Universidade de São Paulo; 2008. 